\title{
Development of extracorporeal membrane oxygenation in Hong Kong: current challenges and future development
}

\author{
Simon WC Sin ${ }^{1,2}$ *, MB, BS, FHKAM (Medicine), Karl Young ${ }^{1}$, MB, BS, FHKAM (Anaesthesiology) \\ ${ }^{1}$ Department of Adult Intensive Care, Queen Mary Hospital, Pokfulam, Hong Kong \\ ${ }^{2}$ Department of Medicine, The University of Hong Kong, Pokfulam, Hong Kong
}

Hong Kong Med J 2017;23:216-7

DOI: $10.12809 / \mathrm{hkmj} 175065$

Reviews of the clinical application of venovenous (VV) and venoarterial (VA) extracorporeal membrane oxygenation (ECMO) were published in the April and June issues, respectively, of the Hong Kong Medical Journal. ${ }^{1,2}$ These issues have presented practical aspects of ECMO, including recent technological advances, practical physiology, patient selection, bedside management, complications, and current evidence. Here, we will discuss about the development of ECMO in Hong Kong.

\section{The present}

Fifty years have passed since the first successful clinical application of ECMO. Over these decades, despite a lack of robust supportive data, ECMO has been used for severe respiratory and cardiac failure refractory to conventional treatment. With the global H1N1 influenza outbreaks of 2007-2008 and 2008-2009, ECMO experienced a resurgence in use to support patients with acute respiratory distress syndrome (ARDS) who failed conventional mechanical ventilation. In 2010, five ECMO centres focusing on VV-ECMO were established under the governance of the Coordinating Committee in Intensive Care Units (COC ICU) of the Hong Kong Hospital Authority. The goal was to provide accessible ECMO facilities during an influenza outbreak. Since that time, these ECMO services have faced a steady increase in service demand, especially for VA-ECMO (unpublished data from ECMO workgroup, COC ICU). This trend is similar to that for international registry data published by the Extracorporeal Life Support Organization (ELSO). ${ }^{3}$

Current ECMO support provided by ICUs is not confined to VV-ECMO for patients with severe ARDS. Most ECMO ICUs also provide VA-ECMO support for patients with severe circulatory failure and some to rescue patients with refractory cardiac arrest. The early local survival outcomes appear comparable with international data. ${ }^{4}$

As a sophisticated technology, there is a grave risk of patient harm from human error and equipment failure, necessitating a higher level of vigilance, staff training, and equipment maintenance. Moreover, ECMO remains a low-volume clinical activity. This 'high-risk low-volume' nature of ECMO means globally, nursing and medical clinical educators need to develop ECMO simulation education programmes to improve clinical practice. Simulation training has been used to train novice ECMO providers, to refresh experienced ECMO users, and to enhance team communication during ECMO crisis management. It may also be part of an ECMO credentialing programme. $^{5}$

Although there is as yet no demonstrable mortality benefit for simulation training in ECMO, most studies have shown an improvement in selfperceived confidence and knowledge of ECMO. ${ }^{6}$ Some have demonstrated shorter ECMO cannulation times after simulation. ${ }^{7}$ In Hong Kong, some ECMO educators, with the support of the Hospital Authority and Asia-Pacific Chapter of the ELSO, have organised ECMO simulation training for local ECMO providers and those in South-East Asia. Feedback indicates a high level of satisfaction from local and international attendees.

How ECMO developed in Hong Kong deserves mention. Such technique evolved from perfusionistrun cardiopulmonary bypass in the operating theatre. When ECMO then emerged as an ICU service, it was heavily reliant on perfusionists, ${ }^{8}$ or at least required perfusionist support in most centres. ${ }^{9}$ This created manpower stress and financial concern for the hospital administrator, especially during the $\mathrm{H} 1 \mathrm{~N} 1$ pandemic when there was a lack of ECMO-trained staff to meet the demands for service. In 2010, ELSO guidelines advised that nurses could be trained as 'ECMO specialists', ${ }^{10}$ especially when a perfusionist may not be readily available. Globally, there are variations in practice; 'ECMO specialists' can be doctors, nurses, perfusionists, or respiratory therapists. ${ }^{9}$

With the latest-generation miniaturised and simplified ECMO circuits, less technical expertise is required. As a result, in Hong Kong, many units have not used perfusionists in the establishment and running of an ECMO service. In Hong Kong, the nursing-led bedside care model, the 'single caregiver model', that complements ECMO physicians has dominated, and contributed to a successful roll-out of Hong Kong ECMO services over a relatively short period of time.

\section{Challenge}

The planning of future ECMO services will be a 
challenge for the Hospital Authority. First, it is an expensive, labour-intensive technology associated with life-threatening complications that lacks unequivocal evidence to support its generalised use over conventional therapy. High-level-evidence recommendations to initiate ECMO are lacking, leading to highly variable practices: across countries, across institutions, and even within one ICU. ${ }^{11}$ Ironically, the use of ECMO is increasing despite the lack of supportive evidence. Quintel et $\mathrm{al}^{12}$ pointed out that the burgeoning use of VV-ECMO in Germany and the United States may be driven by national regulations, reimbursement policies, financial interests, fascination with new gadgets, and ambition rather than solid clinical evidence. Chen et al ${ }^{13}$ also reported that the internet and newspapers tend to be over-optimistic about ECMO survival and this may result in unrealistic requests from or expectations of the general public. The development of a local registry is urgently needed to monitor the appropriateness of case selection and outcome while awaiting the results of more clinical trials.

Second, there is no standard model for an ECMO programme. For example, there are only five ECMO centres in the United Kingdom whereas in France and Germany, the number of centres is unrestricted. In 2012, the ELSO published a consensus paper by an international group of ECMO physicians and health care workers. The focus of the paper provided an insight into various aspects of organising an optimal and safe ECMO programme for adults with acute respiratory failure. ${ }^{14}$ It concluded that a restrained approach was advisable until further evidence is available. This paper can provide a framework when hospital administrators consider a new ECMO programme.

\section{Future}

The use of VA-ECMO for cardiac arrest refractory to conventional cardiopulmonary resuscitation (CPR) is a rapidly expanding indication for ECMO. The technique, VA-ECMO, maintains cerebral circulation during circulatory arrest and facilitates rescue cardiac interventions, eg percutaneous cardiac intervention, during the arrest period. It usually involves multidisciplinary collaboration, eg emergency physicians, cardiologists and intensivists, and a welltrained resuscitation team who can maintain goodquality CPR while ECMO cannulation is performed in the emergency situation. ${ }^{15}$ Nonetheless despite a seemingly good outcome in a large case series, the lack of randomised controlled trial data and potential ethical issues ${ }^{16}$ prohibit its widespread use during resuscitation.

To conclude, ECMO is a developing technology with substantial potential in patients with critical cardiorespiratory failure. It may also be a double-edged sword, however, given its significant complications. More data are required before widespread use of ECMO can be advocated. Finally, in order to maximise the benefit of ECMO technology, an ECMO programme director and hospital administrator should focus on quality and safety.

\section{Declaration}

Dr SWC Sin is the Education Co-chair of Extracorporeal Life Support Organization Asia-Pacific Chapter.

\section{References}

1. Ng GW, Yuen HJ, Sin KC, Leung AK, Au Yeung KW, Lai KY. Clinical use of venovenous extracorporeal membrane oxygenation. Hong Kong Med J 2017;23:168-76.

2. Ng GW, Yuen HJ, Sin KC, Leung AK, Au Yeung KW, Lai KY. Clinical use of venoarterial extracorporeal membrane oxygenation. Hong Kong Med J 2017;23:282-90.

3. ECLS Registry report. International summary. January 2016. Available from: https://www.elso.org/Portals/0/Files/ PDF/International Summary January 2016 FIRST PAGE. pdf. Accessed Apr 2017.

4. Stub D, Bernard S, Pellegrino V, et al. Refractory cardiac arrest treated with mechanical CPR, hypothermia, ECMO and early reperfusion (the CHEER trial). Resuscitation 2015;86:88-94.

5. Johnston L, Oldenburg G. Simulation for neonatal extracorporeal membrane oxygenation teams. Semin Perinatol 2016;40:421-9.

6. Chan SY, Figueroa M, Spentzas T, Powell A, Holloway R, Shah S. Prospective assessment of novice learners in a simulationbased extracorporeal membrane oxygenation (ECMO) education program. Pediatr Cardiol 2013;34:543-52.

7. Allan CK, Pigula F, Bacha EA, et al. An extracorporeal membrane oxygenation cannulation curriculum featuring a novel integrated skills trainer leads to improved performance among pediatric cardiac surgery trainees. Simul Healthc 2013;8:221-8.

8. Mongero LB, Beck JR, Charette KA. Managing the extracorporeal membrane oxygenation (ECMO) circuit integrity and safety utilizing the perfusionist as the "ECMO Specialist". Perfusion 2013;28:552-4.

9. Daly KJ, Camporota L, Barrett NA. An international survey: the role of specialist nurses in adult respiratory extracorporeal membrane oxygenation. Nurs Crit Care 2016 Sep 21. Epub ahead of print.

10. ELSO Guidelines for training and continuing education of ECMO specialists. February 2010. Availablefrom: https://www. elso.org/Portals/0/IGD/Archive/FileManager/97000963d 6cusersshyerdocumentselsoguidelinesfortrainingandcontinuing educationofecmospecialists.pdf. Accessed Apr 2017.

11. Kuo KW, Barbaro RP, Gadepalli SK, Davis MM, Bartlett RH, Odetola FO. Should extracorporeal membrane oxygenation be offered? An international survey. J Pediatr 2017;182:107-13.

12. Quintel M, Gattinoni L, Weber-Carstens S. The German ECMO inflation: when things other than health and care begin to rule medicine. Intensive Care Med 2016;42:1264-6.

13. Chen YY, Chen L, Kao YH, Chu TS, Huang TS, Ko WJ. The over-optimistic portrayal of life-supporting treatments in newspapers and on the Internet: a cross-sectional study using extra-corporeal membrane oxygenation as an example. BMC Med Ethics 2014;15:59.

14. Combes A, Brodie D, Bartlett R, et al. Position paper for the organization of extracorporeal membrane oxygenation programs for acute respiratory failure in adult patients. Am J Respir Crit Care Med 2014;190:488-96.

15. Rousse N, Robin E, Juthier F, et al. Extracorporeal life support in out-of-hospital refractory cardiac arrest. Artif Organs 2016;40:904-9.

16. Riggs KR, Becker LB, Sugarman J. Ethics in the use of extracorporeal cardiopulmonary resuscitation in adults. Resuscitation 2015;91:73-5. 